\title{
A Study on Generic Representation of Human Skeletal Remains Replication of Prehistoric Burial
}

\author{
C.W. Shao ${ }^{\mathrm{a}, *}$, H.L. Chiu ${ }^{\mathrm{b}}$, S.K. Chang ${ }^{\mathrm{c}}$ \\ ${ }^{\text {a }}$ National Tainan University of the Arts, Taiwan - wongwong73@ hotmail.com \\ ${ }^{\mathrm{b}}$ Institute of Anthropology, National Tsing Hua University, Taiwan - chiu_alex@ @otmail.com \\ ${ }^{\mathrm{c}}$ Institute of Cultural Heritage Preservation Research, Bureau of Cultural Heritage, Ministry of Culture, Taiwan - \\ chtn0226@boch.gov.tw
}

KEY WORDS: Skeletal Remains, 3D Scanning, Reverse Engineering, Rapid prototyping

\begin{abstract}
:
Generic representation of skeletal remains from burials consists of three dimensions which include physical anthropologists, replication technicians, and promotional educators. For the reason that archaeological excavation is irreversible and disruptive, detail documentation and replication technologies are surely needed for many purposes. Unearthed bones during the process of 3D digital scanning need to go through reverse procedure, 3D scanning, digital model superimposition, rapid prototyping, mould making, and the integrated errors generated from the presentation of colours and textures are important issues for the presentation of replicate skeleton remains among professional decisions conducted by physical anthropologists, subjective determination of makers, and the expectations of viewers. This study presents several cases and examines current issues on display and replication technologies for human skeletal remains of prehistoric burials.

This study documented detail colour changes of human skeleton over time for the reference of reproduction. The tolerance errors of quantification and required technical qualification is acquired according to the precision of 3D scanning, the specification requirement of rapid prototyping machine, and the mould making process should following the professional requirement for physical anthropological study. Additionally, the colorimeter is adopted to record and analyse the "colour change" of the human skeletal remains from wet to dry condition. Then, the "colure change" is used to evaluate the "real" surface texture and colour presentation of human skeletal remains, and to limit the artistic presentation among the human skeletal remains reproduction.

The "Lingdao man No.1", is a well preserved burial of early Neolithic period (8300 B.P.) excavated from Liangdao-Daowei site, Matsu, Taiwan, as the replicating object for this study. In this study, we examined the reproduction procedures step by step for ensuring the surface texture and colour of the replica matches the real human skeletal remains when discovered. The "colour change" of the skeleton documented and quantified in this study could be the reference for the future study and educational exhibition of human skeletal remain reproduction.
\end{abstract}

\section{INTRODUCTION}

\subsection{Research subject}

The Matszu archipelago located at the northwest part of Taiwan (Figure 1). Through archaeological excavation, skeletal remains form the human burial is named LDDW- I -M01(hereinafter referred to as M01). Ams ${ }^{14} \mathrm{C}$ dating shows about 8,300 years ago, and the skeletal remains of the human burial belongs to the early Neolithic Age in this region. This study investigates the skeletal remains from the M01 (Figure 2) with a half in-situ condition (Chiu, 2013). Half in-situ refers to due to the consideration of weather, devices and materials shipment, and electricity supply, the skeleton remains were kept in the original positions and shipped with the human burial and surrounding soil covered back to the indoor environment for preservation (Figure 3) before indoor cleaning and documentation instated of the in-situ synchronized documentation of stratum, topology, landscape, and the human burial.

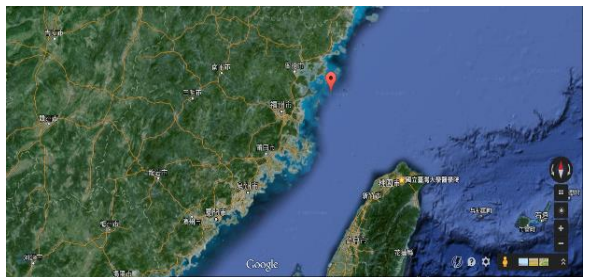

Figure 1. The location of Liangdao site(the red tag) (Source:Google Map, 2015)

The research subject of this study is a male adult who died at the age about 30 in a flexed position with both upper and lower limbs bent to the left side of the body. The features of the bones include extremely well-developed muscle ridge line. The thickness of the bone for this individual indicates energetic muscular activity, evidenced by strong body structures , especially on the limbs. A stout and muscular ridge line (deltoid tuberosity) is very well developed, the outer edge of the distal humerus has a pronounced columnar edge. The lower edge of the

* Corresponding author. 
tuberosity of ulna is very well developed, along with a radial notch lower edge lipping and developed supinator crest. Lower limbs are also robust, muscular ridge line, and the flat tibial level is not high. Compared to the developed state on the limbs, there is obviously a considerable degree of difference.

(Chen \& Chiu, 2013). In-situ condition and the presentation of physical features of the bones are the focuses of this study.

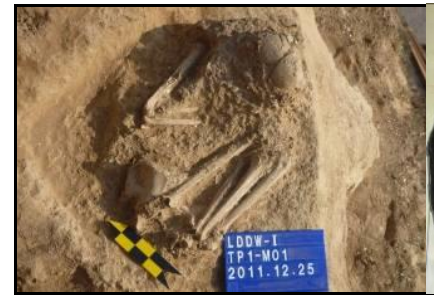

Figure 2. Unearthed condition of the burial

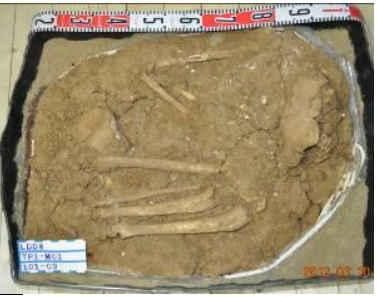

Figure 3. Burial moved to indoors
In addition to soil, ecological remains, and scattered artificial remains, the most important elements are the geometric modelling and the visual representation of texture and colour. The body position presented after cleaning out the soil covered human remains in the archaeological burial presents the records of non-destructive 3D scanning.

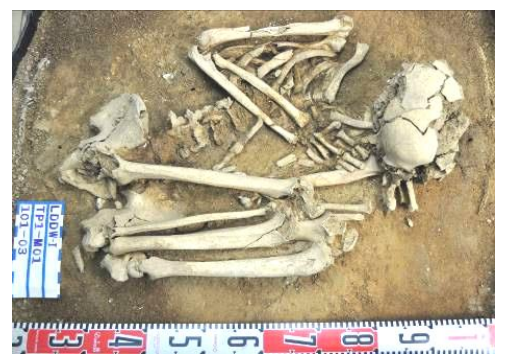

Figuer 4. The condition of burial after cleaning.

M01 was unearthed under the Shell Midden Stratum. Archaeologists first found a broken piece of skull exposed on the fragment of shell middens and were suspicious that was impacted by weathering conditions (temperature, humidity, and ultraviolet rays) to show the significant colour difference with that of unearthed human remains (Figuer 5) in terms of stronger lightness and lower chroma.- After the discovery, the colour difference decreased and became stable several months later (about three to four months) after the piece was cleaned and placed under more stable environmental control (at the temperature between $20^{\circ} \mathrm{C} \sim 24^{\circ} \mathrm{C}$ and relative humidity between $50 \% \mathrm{RH} \sim 60 \% \mathrm{RH})$. According to this observation, it is assumed that after unearthed and removed from the burial environment, human remains change the surface colour, but under the stable environmental control, colour change decreases and becomes stable. Thus, this study concludes that the colour and texture of human remains replication should refer to those in the unearthed condition or at the stable stage of colour change after cleaning. In order to further explore this issue about the possible factors that change the colour of human remains after unearthed, this study uses experimental human remains (skull collected from the historical site at the Elementary Department of National Nanke International Experimental School (NNKIEH) and M01 surrounding soil of the archaeological burial as the samples via scientific analyses (spectrophotometer and composition analyser). The above experimental results then are considered in the human remains replication for colour adjustment and modification.
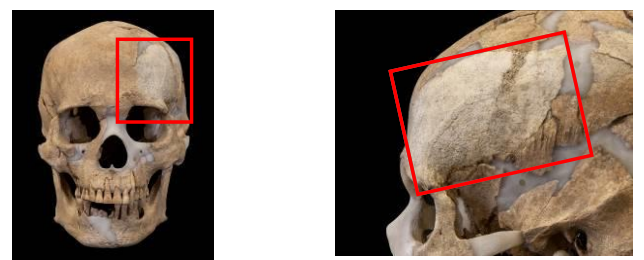

Figuer 5. Left part of frontal bone of skull exposed on shell middens stratum profile (red square)

\subsection{Research purpose}

Salvage Archaeology aims to improve the efficiency of field excavation by using materials such as silicon, unsaturated resin, and glass fibre to conduct in-situ cover of the burial for the preservation at another site after relocation as well as the indoor demouding before cleaning and documentation. Thus, it is also easy for a burial to be contaminated by the covering materials, and so do biochemical and absolute dating analyses.

The main research subject of this study is the human remains from the archaeological burial; the replication of burial human remains involves the application and study of 3D laser scanning, rapid prototyping, fitting moulding, and simulation colour and serves as the first case for Taiwan's archaeological field to practically adopt 3D scanning and digital records and outputs to replicate burial human remains. It helps to enhance the scientific, preservation, and objectivity value of physical anthropology studies. At the same time, it gives the opportunity for this study to conduct a more in-depth study on the authenticity and exhibition application of replication.

Although Article 3.2 of Implementation Rules for the Cultural Heritage Preservation Law defines unearthed archaeological human remains as "ecofacts" not "antiquities," and they are not regulated by "Rules Governing the Replication and Manufacturing Monitoring of Antiquities of Public Domain." Because these remains belong to the Neolithic Era, this law is not comprehensive enough to protect the unearthed remains with academic and research meaning from damages. Thus, the research procedure of this study still follows the relevant rules governing the replication of antiquities and has been conducted with strict practices. Additionally, human remains in this study were replicated via scientific and objective production and the final "objects" acquired can be regarded as the intentional monuments. Therefore, the representation of M01 archaeological remains created from the art and historical perspectives, and then formed the present-day values. The replication values of burial human remains include four dimensions below:

\subsubsection{Physical Anthropology}

They provide the functions of voucher specimens for various studies such as the standard measurement of human bones, morphological analysis and physical conditions (pathology and injuries).

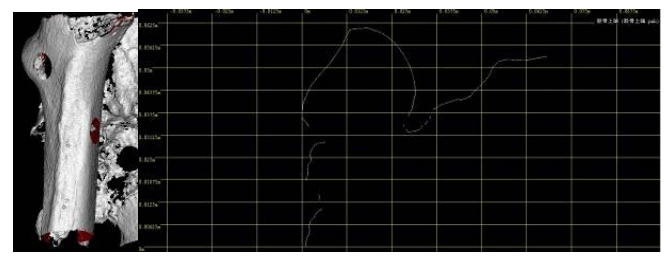

Figuer 6. Left:3D; Right: Qualification Profile

\subsubsection{Exhibition function and educational functions}

This study overcame the difficulty of the remote location of this archaeological site to provide the on-site feeling for the 
public and to enable them to acquire correct archaeological knowledge from the replication and even generate new insights from the module simulation.

\subsubsection{Digital archive}

Unearthed remains are often single or scarce original cultural artefacts that cannot be exhibited. Through the digitalization of replication process, replication, researches, and multimedia presentation without spatial limitation can be realized.

\subsubsection{Cultural asset values}

According to the science of art concept of Alois Rirgl, replicated objects has the values of objective information and dating, replication crafts have the artistic value, and modern technology has the value of practical use (Chen Pin, 2002).

\subsection{Research procedure and technologies}

There are three phases of replication process. At Phase 1, skull was cleaned and glued for 3D scanning; Phase 2 was the output of rapid prototyping; and Phase 3 included the digital replication of prototyping, mould production, trimming, material production, and colouring.

Phase 1: Reversed Engineering was conducted for replication sampling after pre-treatment of burial human remains such as cleaning and gluing. A handheld red laser 3D scanning device (Creaform VIUscan) was used to scan the whole burial.

Phase 2: The digital module was converted into a STL file to produce the entity module via rapid stereotyping. The output equipment used ProJet SD3510 Plus (with the resolution of: $750 \times 750 \times 890 \mathrm{DPI})$ to reach the minimum thickness of $0.029 \mathrm{~mm}$. The theory behind is light-activated resin polymerization for prototyping by using UV Curable Acrylic Plastic as the material. The light-activated polymerization gives high resolution results, but there are limitations to the use of device technologies and fine lines in the final product. After measurement evaluation, these fine lines have no impacts on the presentation of morphological types of the skull (Figure 7).

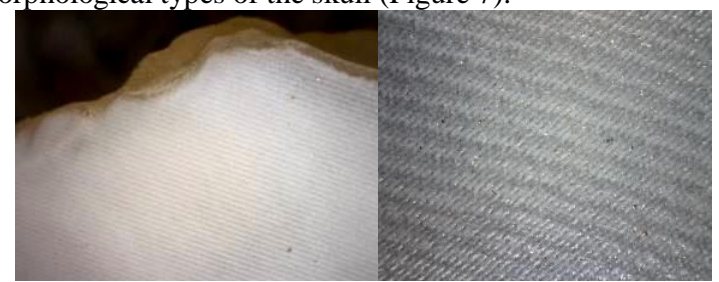

Figure 7. Left: Fine Line ; Right: PR Prototyping

Phase 3: This step kept the completeness of rapid prototyping of the mould. The continuous replication of burial human remains all followed this procedure. In the end, surface texture and colour making of bones were added to this replication to get the feeling of the existing burial.

There should be principles of the replication of archaeological artefacts, and this study respectively describes the ethics of replication principles, high quality, identifiability, and management.

In order to ensure human remains specimens free of contamination, in the pre-treatment, 3D scanning and reverse engineering output were adopted to produce the replication. Although contact replication (such as the use of entity mould) allows us to acquire the most authentic surface texture, features, and prototyping, yet it is easy to damage and contaminate human remains structure. The main research subject needs to be preserved with the best conditions of skeleton, so the contact replication method should be avoided. Principles below should be followed for the replication of human remains:

\section{(1) Legitimacy}

The burial specimens of this study are not the artefacts of the public domain. But they were assessed, monitored, and produced by an expert group established by the preservation and management organization (institution) for the completeness and legitimacy of the research subjects of this study. The replication process was assessed respectively in each phase. Opinions of the valuation committee were taken to adjust and amend necessary replication technology procedure and replicated objects.

\section{(2) Safety}

During the replication process, materials of specimens could not be altered, damaged, fragmented, and changed, and under the strictest conditions, specimens were moved and observed. The following safety principles were observed.

\section{A. No destruction}

No defection, peeling off, and coating of human remains specimens should be proved. When holding and moving the specimens, the operator should have safety protection and receive the monitoring and observation of an archive manager.

\section{B. No contamination}

The human remains specimens were used for the study of physical anthropology, and from replication to colouring, possible contact contamination might have occurred in each phase. As a result, the environment, personnel in contact, as well as production materials and technologies were strictly controlled.

Artificial contamination refers to pollutants generated during collection, in-situ protection or specimen packing, for example, specimen tags of sclerotin of gelatine. During specimen collection and packing, other pollutants such as chemical materials of pesticide, PVA, and PEG, ash, as well as paper tags and package. Researchers in each phase of this study from archaeological excavation to 3D scanning wore full body protective clothing and used tools cleaned with the chemical agent for disinfection to prevent from contamination as well as the minimum interruption of 3D scanning to document unearthed burial human remains.

\section{No change}

Human remains should not be accelerated in damages such as aging, deterioration, and fracture due to the replication. There should be no changes of physical and chemical properties in the surface, texture, materials, and weight of the original objects.

\section{(3)High quality}

According to the article 5 of the "Rules Governing the Replication and Manufacturing Monitoring of Antiquities of Public Domain," of Taiwan. "If the prototyping or quality of replication is distorted or poor, replication and re-replication should be terminated, and those defected replication and rereplication completed should be destroyed under monitoring." The replicated artefacts should present the prototyping, contents, texture, or features of the original artefacts to avoid reducing the value of the original artefacts. Thus, replication requires the planning and conduction by operators with highest standard techniques as well as the optimal aesthetics.

\section{(4) Identifiability}

It is confusing for archiving and viewers because the burial replication completed is identical to the original one due to the prototyping and texture. Hence, it is necessary to mark with "replication" in the description of archive registration and exhibition education. The replicated artefacts should add with identifiable symbols and patterns, weight information, and other intangible marks during production for the purpose of identification.

After the completion of replicated objects, both replicated and original artefacts were weighted and documented precisely under 
the witness of the authorized agency as the direct identification for them.

\section{(5) Management}

Replicated objects were suggested to be documented with relevant replication information, photos, and descriptions on the record cards by management (preservation) agency for future archive management and identification. The lending of replicated objects should be managed with books. The replication agency should manage the moulds, test items, and quantities of replication with book description to prevent from launching to the commercial market.

\section{RESEARCH PROCESS}

Burial replication requires a series of technological practices, and it is not a single-way process but the functional systematic connection that features different preservation method and loop in each phase. The modification and adjustment of each step affects the results of other steps. The covered steps and system are shown below: :

\subsection{D scanning technique}

3D scanning technique has the advantages of accuracy and non-contact measurement as the important means for information collection and storage (Wan, 2013). Archaeological excavation and documentation also requires the use of measurement technique to explore physical features as well as morphological changes and development pattern.-Normally, physical anthropologists measure skull and bones, and archaeologists need to clearly point out burial contents including the unearthed structure of stratum, coffin pit, funeral instrument and objects, and body decorative appraisals. In short, there are three dimension of records (Chiu, 2014).

Dimension 1: Unearthed contextual records (the accompanied relationship of unearthed stratum, spatial position, objects, and phenomena). Dimension 2: In-situ status of the human remains (burial position, direction, bone joint condition). Dimension 3: Physical observation (gender, the judgment of death age, physical features, measurement, pathology, restoration and recovery).

2.2 The human remains were at a complicate position of rising up with twisted limbs. A handset 3D scanner (Creaform VIUscan, 2010) was used to acquire more refined results. Compared to the scanners mounted on a tripod or robotic arm, this canner is smaller and lighter and allows manual operation to scan the target artifact at various angles to ensure to conduct scanning records from multiple angles of the complicate morphology of human remains. The laser 3D scanner is with the specification of Nd:YAG (infrared ray) crosshair laser with the wave length of $1.06 \mu \mathrm{m}$, class $\Pi$; scanning length of $300 \mathrm{~mm}$, resolution of $0.2 \mathrm{~mm}$, and accuracy of $0.05 \mathrm{~mm}$.

During operation, it can be connected directly with an image processor to synchronically display the scanning status. After scanning operation, a digital module of M01 with the average resolution of $0.2 \mathrm{~mm}$ was acquired with the triangle mesh number of 38,381,220 and points of 20,996,437. With the digital module, scale measurement and profile records began for the study on morphology and bone features of human remains (Figure 9).

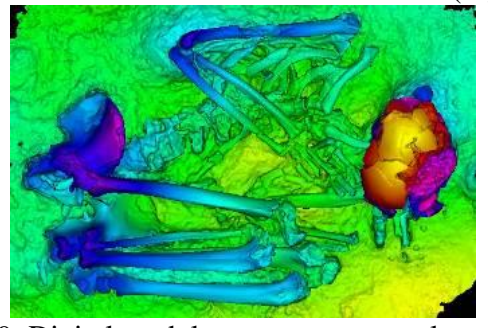

Figure 9. Digital module create contour coloured map.

\subsection{Reverse production}

After digital scanning, the production of entity burial module began with rapid prototyping output and patching. Because rapid prototyping acquire the minimum thickness of $0.029 \mathrm{~mm}$, it could reach the requirement of morphology and feature presentation of human remains. When a module is outputted with resolution of $0.56 \mathrm{~mm}$, due to low resolution, it may result in smooth and insignificant features. It was only with the use of $0.2 \mathrm{~mm}$ output resolution; we were able to meet the quality requirement of bone surface structure. The high resolution of the machine, however, limits the availability of output size $(20 \mathrm{~cm} \times 20 \mathrm{~cm})$, and important features and prototyping borders were avoided during zoning. There were total 17 zones divided to output, and the average thickness of the output module is $2.2 \mathrm{~mm}$ (Figure 10).

The output of burial module was inspected on site for any deformation or errors. Microscopes were used to observe the surface status. There was the existence of sculpture lines, and after evaluation, the presentation requirement of texture, pathology, and features has been met.

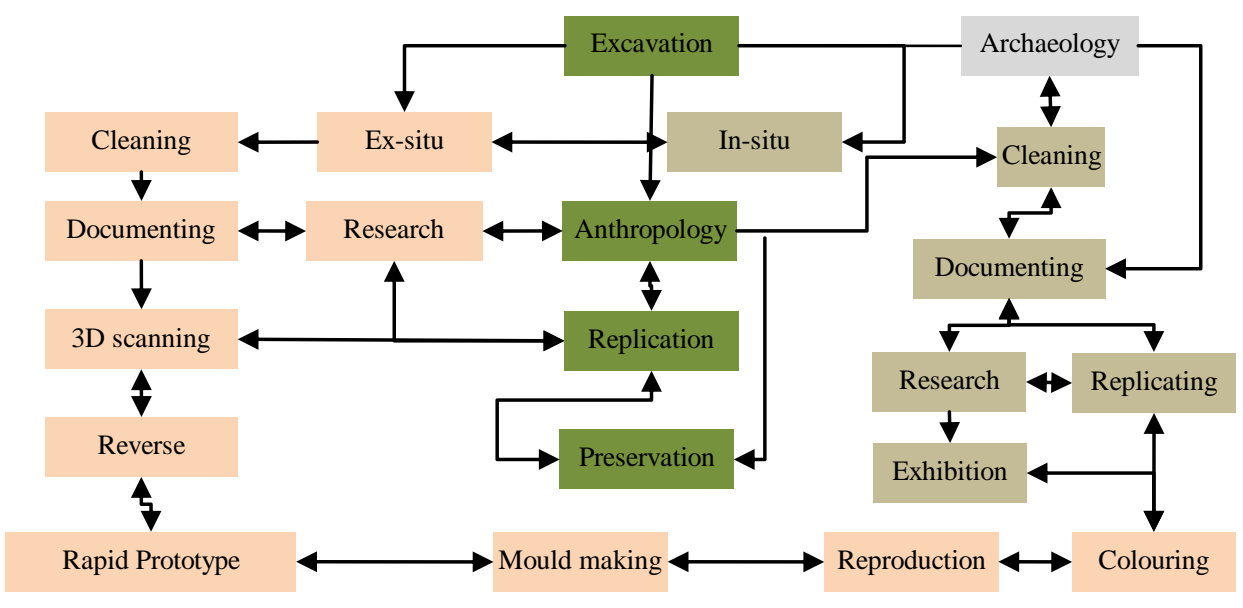

Figure 8. Burial replication and system flow chart. 


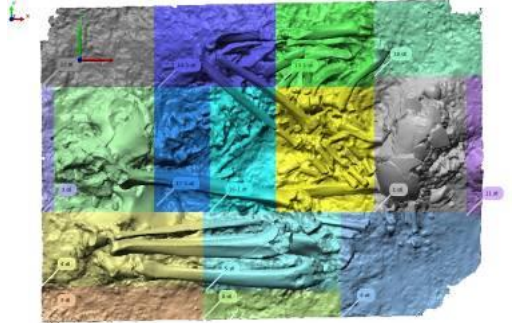

Figure 10. Output planning of burial zones.

In order to keep the 17 output pieces of prototyping, the temporal approach was adopted by using patching with epichlorohydrin $\left(\mathrm{C}_{3} \mathrm{H}_{5} \mathrm{ClO}\right)$, bisphenol- $\mathrm{A} \quad\left(\mathrm{C}_{15} \mathrm{H}_{16} \mathrm{O}_{2}\right)$, and Cyanoacrylate (Figure 11).

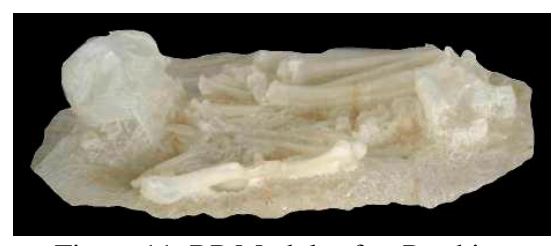

Figure 11. RP Module after Patching

\subsection{Module turning replication}

Papid prototyping used BENTEX SILICONES (S-118 RTV MOULD MAKING ELASTOMER) as the module material to avoid damages to original module and meet the requirement of module turning. To reduce fluidity caused by module turning, $\mathrm{CaCO}_{3}$ powder with the weight ratio of $20 \%$ was added as the aggregate material of silicon that helps to increase silicon strength and avoid deformation that results from long term storage.

In order to keep the completeness of the module during production, two large portions of burial zones were used (upper and bottom), and each of them was divided into four small portions. When dividing the module, the sites of important physical features were avoided the impacts of mould division. The production procedure is described below:

(1)Mould border production: using prototyping materials to divide borders.

(2)Casting transformed silicon: producing soft inner module with the casting of transformed silicon.

(3)Strengthening inner module: patching gauze for twice and coating silicon three times to reinforce the structure.

(4)Production of hold-open device of module: Upper and bottom hold-open devices were produced to increase stability.

(5)Production of mould division line: producing mould portions, the mould divided into four portions.

(6)Completion of blank: production of hard supportive outer mould with the coating of unsaturated resin as well as glass fibre to strengthen the structure.

(7)Mould Production: extracting the prototype from the mould with unsaturated resin and glass fibre to strengthen and to complete mould turning.

(8)Sealing bottom: In order to enhance mould strength, foaming agent was coated inside; unsaturated resin was used to seal the bottom before completing the burial replication.

After the prototyping was finished, the replication with unsaturated resin and $\mathrm{CaCO}_{3}$ began. After replication was removed from the mould, the replication and prototyping output were both examined for defects such as deformation, incompleteness, and bubbles. This process required the involvement and participation of a physical anthropologist to confirm the correctness of the presentation of physical features. The defect of pores was identified, so solid resin was used for filling and replication of bone texture. In the end, slight sand spraying work was conducted to reduce the smoothness on the surface of replicated module (Figure 12).

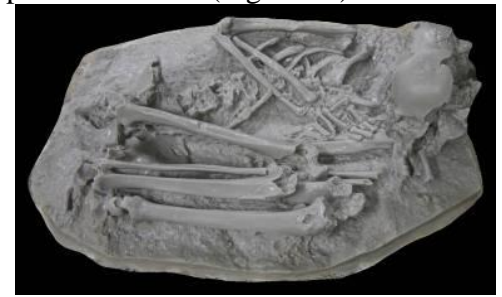

Figure 12. Resin replication of PR prototyping.

\subsection{Colour difference test}

Human bone tissue is easily impacted by various factors of the surrounding environment. That leads to colour formation of exposed human remains. But the surface colour of bone remain changes continuously right after unearthed. When replicating bones, we faced the choice between the initial colour and colour in transformation of human remains.

The basic components of bones are calcium carbonate, phosphate, collagen, and water. Water content of bones is about $25 \%-30 \%$. The unearthed burial human remains were attached with some soil, and it resulted in different surface colour from that of general human remains

The compact cortical bones were the outer layer structure of unearthed human remains, the largest area to be replicated. The research subject M01 was examined about 30 years old at death, an adult. Collagen and water after unearthed began to enter natural drying period. In order to understand the colour change of dried organic materials, this study observed the water saturation and absolute dryness of human bones (at $105^{\circ} \mathrm{C}$ for drying for 24 hours), and soil surrounding the unearthed burial was conducted with main component and colour change tests to explore major factors of human bone colour change.

\subsubsection{Colour records}

Minolta CD-2600 Spectrophotometer was used for nondestructive test as the measurement of colour difference with the caliber size of $\phi 5 \mathrm{~mm}$, light source of D65, and angle of view at $10^{\circ}$. The system was CIE certified $\mathrm{L}^{*} \mathrm{a} * \mathrm{~b} *$ respectively presenting lightness $\left(\mathrm{L}^{*}=100\right.$ white and $\mathrm{L}^{*}=0$ black ); chroma and hue ( $a^{*}$ positive value, red, and negative value, green; $b^{*}$ positive value, yellow, and negative value, blue ) . Various colours are shown in formulas below, and five measurements were conducted for the average value. Values were recorded on SCI100 reflective pattern. CIE1976 L* a*b* lightness spatial measurement colour standard was adopted, and standard white board (calibration standard NPL) was used as the basis:

$$
\begin{aligned}
& \mathrm{L}^{*}=116(\mathrm{Y} / 100) 1 / 3-16 \\
& \mathrm{a}^{*}=500[(\mathrm{X} / 94.81) 1 / 3-(\mathrm{Y} / 100) 1 / 3] \\
& \mathrm{b}^{*}=200[(\mathrm{Y} / 100) 1 / 3-(\mathrm{Z} / 107.34) 1 / 3]
\end{aligned}
$$

\subsubsection{Colour tests}

It was assumed that the colour change of cortical bone may result from collagen, water, and iron in the soil. Changes were tested as described below:

(1) Periosteum is the compact fibre film on the surface of the bone, divided into outer layer (fibre) and inner layer (cell layer). 
The outer layer mainly consists of collagen fibre and nerve fibre. The outer layer of bones received outer impacts. Thus, the earlier changes occur herein that affects the colour outlook of bones.

The experimental sample was collected from human remains exposed in the natural environment. Under three conditions of natural dry environment (about $25^{\circ} \mathrm{C}$ and $60 \% \mathrm{RH}$ ), it was soaked in deionized water ( 24 hours) and baked in the oven for absolute dryness $\left(105^{\circ} \mathrm{C}, 24\right.$ hours $)$. Spectrophotometer was used for colour records, and a colour difference test was conducted (Figure 13).
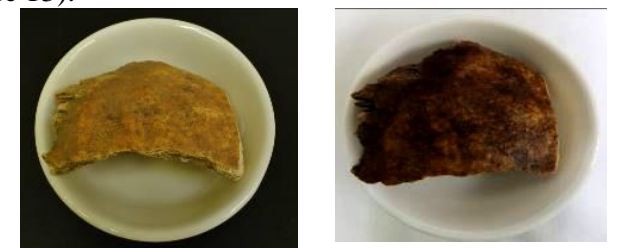

Figure 13. Absolutely dry human bone sample (left); mixed with water human bone sample (right).

Based on the experiment results, the water content of bones, under natural dry condition (air dried), was about $26.17 \%$ while under water saturation, the water content of bones was about 44.19\% (Table 1). The difference in between reached $18.02 \%$.

\begin{tabular}{|l|c|}
\hline \multicolumn{1}{|c|}{ Status of human bones } & Water content \\
\hline Weight of bones (air dried) & $20.3 \mathrm{~g}$ \\
\hline Absolute weight of bones (oven dried) & $16.09 \mathrm{~g}$ \\
\hline Weight of water in bones (air dried) & $4.21 \mathrm{~g}$ \\
\hline Water content of bones (air dried) & $26.17 \%$ \\
\hline Saturated weight of bones & $23.2 \mathrm{~g}$ \\
\hline Weight of water in bones (saturation) & $7.11 \mathrm{~g}$ \\
\hline Water content of bones (saturation) & $44.19 \%$ \\
\hline
\end{tabular}

Table 1. Physical characteristics of experimental bone sample.

Thus, it was known that due to the exposure to water, the experimental sample of human bones also dehydrated to result in the increased lightness and decreased hue of bone colour. When air dried human bones were used for the standard values, through tests, we knew air dried Lab value (SCI) and water saturated Lab (SCI) have the colour difference value respectively $\mathrm{L}^{*}-8.68$; $\mathrm{a}^{*}$ 2.92 ; and $b^{*}-7.86$. These changes showed the total colour difference of $\Delta E * a b, 9.17$ and NBS of $\Delta E * a b$ reaching more than 6 , the much level of colour difference. The difference resulted mainly from lightness change to darkness with $b^{*}$ value (significantly bluish) reaching to this level. Additionally, a* value (inclining to green colour system) also reached to the noticeable level. Thus, when the unearthed burial is changed from water saturated status to air dried status, bones will have very significant colour changes. Furthermore, when human bones under water saturation are used as standards, colour difference between water saturated and air dried values (SCI) has $\mathrm{L}^{*}, 14.71$, $a^{*}-0.89$, and $b * 0.63$. These values showed the total colour difference $\Delta E * a b, 14.75$, resulting mainly from the change of lightness with small changes of $a^{*}$ (greenish) and $b^{*}$ (yellowish). But these changes reached to the slight level. The above tests indicated water content of human bone sample reaches as high as $44.19 \%$ significantly affecting lightness and less significantly affecting chroma (Table 2).

(2) Soil inside the burial contains rich iron (Table), and that causes the shift of cortical bond surface to the red colour system due to the possible absorption of iron ion to the bone surface caused by the soil residual, especially, with the iron level reaching higher than $60 \%$. Iron elements such as $\mathrm{FeO}(\mathrm{OH}) . \mathrm{x}$ $\mathrm{H}_{2} \mathrm{O}$ show yellow colour, $\mathrm{Fe}_{2} \mathrm{O}_{3}$ red to red brown colour, and $\mathrm{FeO} . \mathrm{Fe}_{2} \mathrm{O}_{3}$ black colour. It is assumed that the possible reason for the reddish colour of unearthed human remains in chroma and dark in lightness are the attachment of soil residual and attachment of iron ion.

In order to understand the components of soil around M01 burial, a handheld Innov-X XRF was used for soil sample analysis (soil collected from in-situ M01) to detect the significant existence of iron elements (Table 3). Although the component analysis did not conduct qualitative or quantitative analysis, yet the reactive strength proved the existence of quantitative changes.

\begin{tabular}{|l|r|l|r|l|r|}
\hline $\begin{array}{c}\text { Absolutely dry } \\
\text { Lab (SCI) }\end{array}$ & \multicolumn{2}{c|}{$\begin{array}{c}\text { Air dried Lab } \\
\text { (SCI) }\end{array}$} & \multicolumn{2}{c|}{$\begin{array}{c}\text { Water saturated } \\
\text { Lab(SCI) }\end{array}$} \\
\hline \multicolumn{2}{|c|}{ Average } & \multicolumn{2}{c|}{ Average } & \multicolumn{2}{c|}{ Average } \\
\hline $\mathrm{L}^{*}$ & 52.65 & $\mathrm{~L}^{*}$ & 46.62 & $\mathrm{~L}^{*}$ & 37.94 \\
\hline $\mathrm{a}^{*}$ & 8.81 & $\mathrm{a}^{*}$ & 12.62 & $\mathrm{a}^{*}$ & 9.70 \\
\hline $\mathrm{b}^{*}$ & 19.21 & $\mathrm{~b}^{*}$ & 26.44 & $\mathrm{~b}^{*}$ & 18.58 \\
\hline Weight & $16.09 \mathrm{~g}$ & Weight & $20.03 \mathrm{~g}$ & Weight & $23.2 \mathrm{~g}$ \\
\hline \multicolumn{4}{|c}{$\Delta \mathrm{E} *$ ab:14.75 } \\
\hline \multicolumn{5}{|c}{$\Delta \mathrm{E}^{*} \mathrm{ab}: 9.17$} \\
\hline
\end{tabular}

Table 2. Colour changes of human bone sample.

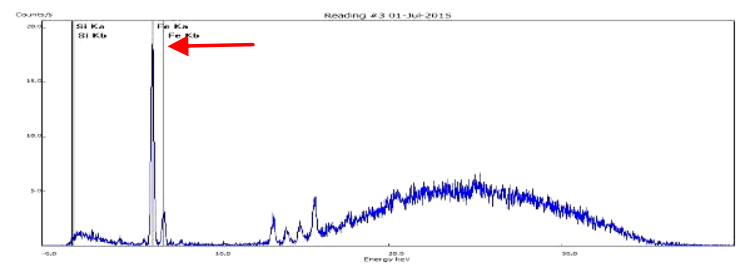

Table 3 .Component Analysis of Soil Surrounding the Burial

For colour change of soil, soil collected from burial M01 was naturally dried (about $25^{\circ} \mathrm{C}$ and $60 \% \mathrm{RH}$ ), mixed with deionized water, and absolutely dried in the oven $\left(105^{\circ} \mathrm{C} / 24\right.$ hours $)$. Spectrophotometer was used for colour recording, and a colour difference test was conducted.
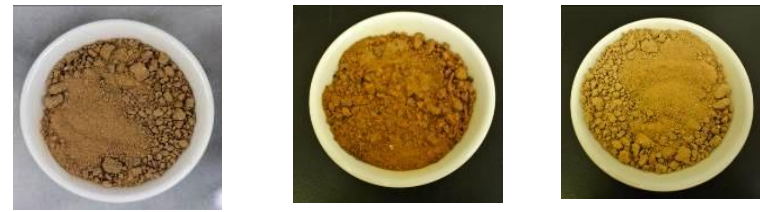

Figure 14. Soil tests(left: naturally dry; middle: mixed with deionized water; right: absolutely dry)

After dried by the natural air the water content of soil was about $1.61 \%$. This test used a dropper to add deionized water into the soil. Spectrophotometer was used for the measurement of colour differences, and results are shown as in Table 4.

\begin{tabular}{|l|c|}
\hline \multicolumn{1}{|c|}{ Soil status } & $\begin{array}{c}\text { Weight \& } \\
\text { water content }\end{array}$ \\
\hline Weight of soil (air dried) & $35.34 \mathrm{~g}$ \\
\hline Weight of soil (absolutely dried, $105^{\circ} \mathrm{C}$ ) & $34.78 \mathrm{~g}$ \\
\hline Weight of water inside soil (air dried) & $0.56 \mathrm{~g}$ \\
\hline Water content of soil (air dried) & $1.61 \%$ \\
\hline
\end{tabular}

Table 4. Weight and water content of soil sample.

Soil sample was collected from the burial stratum, and after tests, we knew along with the increase of water content of the soil, L value decreased accordingly. Additionally, when soil air dried was used as the standards, the colour difference between Lab 
(SCI) of soil air dried and water saturated showed $\mathrm{L}^{*},-11.88 ; \mathrm{a}^{*}$, 2.64; and $b^{*}, 0.98$. These values indicated total colour difference of $\Delta \mathrm{E} * \mathrm{ab}$ of 11.91 and NBS $\Delta \mathrm{E} *$ ab higher than 6 reaching the much level.

The difference of colour resulted from the dark lightness; additionally, a*(inclining to the red system) reached to the noticeable level while $b^{*}$ (slightly yellowish) reached to the slight level. The burial soil in this test was conducted from air dried (experimental environment) to mixed with water until colour changed significantly.

On the other hand, when the colour of soil mixed with water was used as the standards, the colour difference between Lab values (SCIs) of soil mixed with water and absolutely dried showed $L^{*}$ of 14.7 ; $a^{*}$ of -2.66 ; and $b^{*}$ of -0.37 . From the values, we knew that total color difference of $\Delta E * a b$ of 14.94 mainly because of the change of lightness with $a^{*}$ (greenish colour) reaching the noticeable level, $\mathrm{b} *($ bluish colour) reaching the slight level.

The above tests showed the colour difference between soil samples respectively air dried and absolutely dried has $\Delta \mathrm{E} * \mathrm{ab}$ of 2.88 as well as that between air dried and water saturated has $\Delta \mathrm{E} * \mathrm{ab}$ of 14.94 . That showed the significant change of colour of soil sample along with the change of water content of soil (Table 5).

\begin{tabular}{|l|c|l|c|l|c|}
\hline $\begin{array}{c}\text { Lab value (SCI) of } \\
\text { absolutely dried }\end{array}$ & \multicolumn{2}{|c|}{$\begin{array}{c}\text { Lab value (SCI) } \\
\text { of air dried }\end{array}$} & $\begin{array}{c}\text { Lab value (SCI) } \\
\text { of water saturated }\end{array}$ \\
\hline \multicolumn{2}{|c|}{ Average } & \multicolumn{2}{c|}{ Average } & \multicolumn{2}{c|}{ Average } \\
\hline $\mathrm{L}^{*}$ & 59.72 & $\mathrm{~L}^{*}$ & 56.90 & $\mathrm{~L}^{*}$ & 45.02 \\
\hline $\mathrm{a}^{*}$ & 6.92 & $\mathrm{a}^{*}$ & 6.94 & $\mathrm{a}^{*}$ & 9.58 \\
\hline $\mathrm{b}^{*}$ & 24.61 & $\mathrm{~b}^{*}$ & 24.00 & $\mathrm{~b}^{*}$ & 24.98 \\
\hline Weight & 34.78 & Weight & 35.34 & Weight & 39.49 \\
\hline $\begin{array}{l}\text { Water } \\
\text { content }\end{array}$ & $0.0 \%$ & $\begin{array}{l}\text { Water } \\
\text { content }\end{array}$ & $1.61 \%$ & $\begin{array}{l}\text { Water } \\
\text { content }\end{array}$ & $11.93 \%$ \\
\hline \multicolumn{5}{|c|}{$\Delta \mathrm{E} *$ ab:14.94 } \\
\hline \multicolumn{5}{|c|}{$\Delta \mathrm{E} *$ ab:11.91 } \\
\hline
\end{tabular}

Table 5. Colour change of soil sample.

In summary, from experimental results of water contents and color difference of human remains and soil samples, the difference between samples respectively water saturated and absolutely dried has $\Delta \mathrm{E} *$ ab higher than 14 indicating water content ratio significantly affects the colour change of human remains from the time just being unearthed to a certain period after being unearthed. Because of the huge change of lightness, the soil colour is more likely to be reddish. Although there had been no colour records of M01 when it was unearthed, yet according to test results of this study and the observation from the archaeologists unearthed M01, we are able to assume the presentation of reddish and low lightness of human remains when it was just unearthed.

\subsection{Colouring}

In order to present the texture and colour closest to those of original specimen, colours were put to look for authenticity and the true feelings. Colouring materials include oil paints, waterbased paints, acrylic paints, and mortar. Because some human remains were attached with unearthed residual soil, mortar was then applied appropriately to get close to the feeling of texture.

From being unearthed, human remains continuously and significantly changed their lightness, hue, and chroma. In order to get closest to the current colour status of human remains, this study simulated the colours with higher lightness and lower hue. During colour simulation, we also paid attention to and adjusted concrete presentation of physical features and pathological phenomena before obtaining the final outcome. The procedure of colour replication is described below:

(1)Coating background colour: Dark colours were added in bottom layers to increase the lightness and preserve the texture layer of human remains. This is the first layer of background colour coating (Figure 15)。

(2)The second-layer colour: Brushes were used to create point texture and colour of bones; and with mortar and colour paints, the lightness was improved (Figure 16).

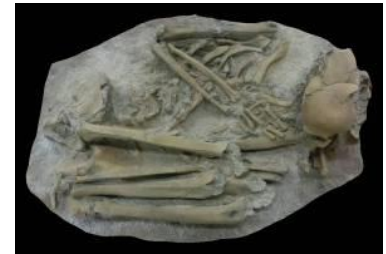

Figure 15. Coating of background colour.

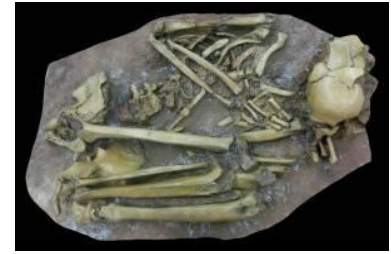

Figure 16.The second-layer colour.
(3)The third-layer colour: The photo images of burial human remains were used as reference for bone texture replication and colour calibration.

(4)Replication of surface texture: Acrylic resin mixed with $\mathrm{CaCO}_{3}$ to produce gesso that replicates the rough texture of human remains. Bonding with burial soil was also tested. In the end, vinyl chloride resin mixed with soil was used to present the closet significant colours and textures.

(5)Surface colour simulation: This procedure presented the out layer's colour and texture. In order to accurately present the visual feeling of burial, we discussed with physical anthropologists and made amendment to use the existing colours of burial remains as the basis for replication rather than the colours shown when they were unearthed.

(6)Replication and colour simulation: After colours replication was completed, mortar was used to create the soil texture. After drying, final colour adjustment and texture replication were conducted (Figure 17).

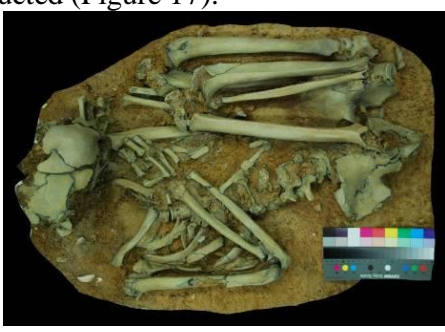

Figure 17. Completion of burial remains replication.

(7)Replication review and comparison: After replication is completed, the accuracy of physical anthropology needed to be proved; colours, textures, morphologies, and bone features need to be close to the authentic statuses. There should be the presentation of protruding muscle ridge lines (Figure 18).
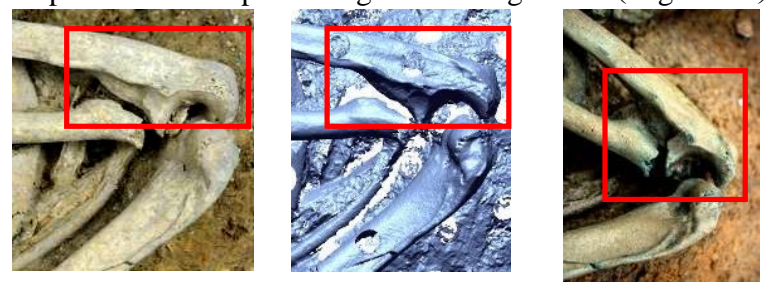

Figure 18. Unearthed human remains (left); digital module (middle); and human remains replication (right). 


\section{RESEARCH RESULTS}

This study investigates the LDDW-I-M01 burial for the purpose of replication. In order to protect the "remains," noncontamination principle was adopted to complete the replication and exhibit publically, the first successful case in Taiwan. Although 3D scanning and rapid prototyping techniques help to have accurate output, but the prototyping of output object needs to go through entity replication before mass production. To avoid deformation and material deterioration and the failure for future uses, we utilized rapid prototyping output to create the mould. Then, used the mould to replicating the M01, and with difficult authentic colour and texture presentation, the replication is able to give more meanings and values to exhibitions and researches.

Artefact replication created through practical technique operation and the research process established by this study for the burial remains replication can be served for the future relevant research discussions and can be the reference for the practical replication techniques.

\subsection{Research discussion}

3.1.1 Replicated works are away from authenticate of artefacts proposed by Jean Baudrillard in "Le Système Des Objets," because when viewers know the objects displayed via exhibition description of museums are "replicated works", it is impossible for viewers to cherish the memories of the past and be obsessed for the authenticity. Yet, the scientific process to replicate burial human remains transforms the life history of the human remains. The replicating works constructed by the comprehensive professional knowledge and techniques included archaeology, physical anthropology, and artefacts preservation, could be transformed into "artefacts" with academic, historical, and valuable meanings in the future.

3.1.2 The burial investigated in this study during 3D scanning was semi-excavated, and thus we were not able to completely record the relevant relationship between remains and unearthed strata. In the future, X-ray computed tomography (CT scan) with higher resolution is likely to be used to completely document the internal burial structure and overcome the light linearity and unpenetrability of $3 \mathrm{D}$ scanning. Then before human remains were unearthed, the researchers are able to fully understand the morphologies and soil contents. More comprehensive background information for the accuracy of biochemical sampling and the possibility to restore human remains can be provided.

\subsection{Research and exhibition suggestions}

Replication of human remains involves the issue of museum ethics. Over emphasis on single unearthed replicated skull may trigger the perception towards "hunting" and "capture." For example, in 1900, the US enacted the "Native American Graves Protection and Repatriation Act" to safeguard the basic rights of the Native American's ancestors free from interruption. Even the discovery of pre-historical remains of Kennewick man was protected by the spirit of the Act (Chiu, 2014 ). The addition of buffering display objects or the method to buffer arrangement of skull, not presented as the direct "display," inspires the viewers to generate the thinking like viewing the hunting prey.

Burial replication should be exhibited with the atmosphere of unearthed burial and detailed photo and text description. The arrangement displayed should coordinate with the remain site's environmental topology to enable viewers to feel the unearthed environment and landscape. By getting closer to the replicated burial (such as height and topology), viewers will have in situ feeling about life during that time. The restoration of life on the map will also help the viewers to know the living environment better and to prevent from the viewing experience of watching "remains".

\section{REFERENCES}

Chen, C.Y., Shao, C.W., Tsai, Y.L., Chang, S.K., 2012. A study of the investigating and recording techniques applying on the remains in archaeological excavation, Taiwan. In: 2012 International symposium on archaeological object conservation, Seoul, Korea.

Chen, C.Y., Chiu, H.L., 2013. The report of the excavation of Daowei sites in Liang Island, Matsu, and human skeleton remains restoration. Dapartment of Cultural Affairs, Lienchiang County, Taiwan.

Chiu, H.L., 2014. Applications of 3D Scanning and Revers Engineering Through The Aspect of Archeology:A Case Study on The Reconstruction of "Liangdao Man",Taiwan. In: Journal of Cultural Heritage Conservation.30:80-110.Bureau of cultural heritage, R.O.C..

Etxaniz, O., Solaberrieta, E., Mingguez, R., Muniozguren, J., Arise, A., 2008. Digital modeling of a human skull. Journal of Achievements of in Materials and Manufacturing Engeering, 27(1), pp. 303-315.

Etxaniz, O., Solaberrieta, E., Mingguez, R., Muniozguren, J., Arise, A., 2008. Digital modeling of a human skull, Journal of Achievements in Materials and Manufacturing Engineering, 27(1), pp. 303-315.

Ko, A.M.S., Chen, C.Y., Fu, Q., Delfin, F., Li, M.K., Chiu, H.L., Stoneking, M., Ko, Y.C., 2014. Early Austronesians: Into and Out Of Taiwan. American Journal of Human Genetics, 94(3), pp. 426-436.

Melvin J. Wachowiak and Basiliki Vicky Karas, 2009. 3D Scanning and replication for museum and cultural heritage applications, Journal of the American Institute for Conservation, Volume 48, page 141-158.

Riegl, A., 2001. A Riegl and Art Science (Chin, P., Trans). China Academy of Art ,China, pp. 315-352. (In Chinese)

Wachowiak, M.J. and Karas, B.V., 2009. 3D Scanning and replication for museum and cultural heritage applications, Journal of the American Institute for Conservation, 48, pp. 141-158.

Wan, H.L., 2013. The application of 3D virtual exhibition technique: A case study of Bengbu Shuangdun No. 1 tomb. Journal of Hubei University of Economics (Humanities and Social Sciences), 10(1), pp. 29-30.

Wang, S.L., Li, L.F., Zheng, M.S., Shao, C.W., Chang, S.K., 2010. The documentation and application of three dimensional investigation techniques: A case study of the stele in Fort Provintia. Institute of Cultural Heritage Preservation Research, Bureau of Cultural Heritage, Ministry of Culture, Taiwan. 